\title{
Analysis of Work-to-Work Bibliographic Relationships through FRBR: A Canadian Perspective
}

\author{
Clément Arsenault \\ École de bibliothéconomie et des sciences de l'information (EBSI), Université de Montréal, \\ Montréal, Canada \\ Alireza Noruzi \\ Department of Library \& Information Science, University of Tehran, Tehran, Iran
}

\begin{abstract}
The purpose of this study is to investigate the characteristics of Canadian publications by analyzing their bibliographic relationships based on the Functional Requirements for Bibliographic Records (FRBR) model. The study indicates frequencies of occurrence of workto-work bibliographic relationships for manifestations published in 2009 and cataloged in the AMICUS online catalog. The results show that approximately $4.4 \%$ of the 2009 bibliographic records in the AMICUS catalog exhibit a work-to-work bibliographic relationship.
\end{abstract}

KEYWORDS: Functional Requirements for Bibliographic Records (FRBR), work-to-work relationships, bibliographic family, cataloging, Canada

\section{INTRODUCTION}

Bibliographic relationships have been at the heart of cataloging theory for more than a century. They can be defined as an association, connection, or interaction between different bibliographic entities, or components of entities. The Functional Requirements for Bibliographic Records (FRBR) conceptual model is built on relationships between and among bibliographic entities. Bibliographic "relationships serve as the vehicle for depicting the link between one entity and another, and thus as the means of assisting the user to 'navigate' the universe that is represented in a bibliography, catalogue, or bibliographic database." "Chapter five of the FRBR Final Report deals specifically with bibliographic relationships.

These relationships are frequently expressed through the use of a note that indicates not only that a relationship exists among entities, but also clearly represents the nature of the relationship. In the FRBR model it is stated that a relationship is not valid unless the entities on each side of the relationship are explicitly identified. ${ }^{2}$ For example, statements such as "based on a novel by Moshe Gaash," "based on an animated short film," "based on a story by Barry Wong," do not explicitly establish a work-to-work relationship, while statements such as "based on the novel Spying on Dracula by Mary Labatt," and "based on the film Passione D'amore directed by Ettore Scola" clearly indicate the target of the relationship.

Identification of bibliographic relationships allows users to navigate between related works and can help information systems designers organize large result sets in a way that is more useful to end users. Collocation devices such as uniform titles (Title of the Work in Resource Description and Access [RDA] 6.2) may be used to that effect although the collocating functions of current library catalogs are generally felt to be unsatisfactory by library users. ${ }^{3}$

\footnotetext{
* Corresponding author: Clément Arsenault, EBSI, Université de Montréal, C.P. 6128, succursale Centre-ville, Montréal, QC H3C 3J7, Canada. E-mail: clement.arsenault@umontreal.ca
} 
The FRBR model highlights the importance of bibliographic relationships and other aspects of bibliographic context for effectively retrieving information. The quality of bibliographic databases often depends on the ability to link entities through relationships. ${ }^{4}$ The emphasis put on adding and maintaining relationships between intellectual works aims to improve the structure of bibliographic databases. As a result, the catalogs and databases serve users more effectively.

The network of bibliographic relationships is complex and thus not always easy to explain and display. Bibliographic relationships between works can be numerous and often more complicated than expected. Works may have supplements, which may be realized as a film, which may have a successor (in the form of a sequel), which could then be adapted into another work (Figure 1).

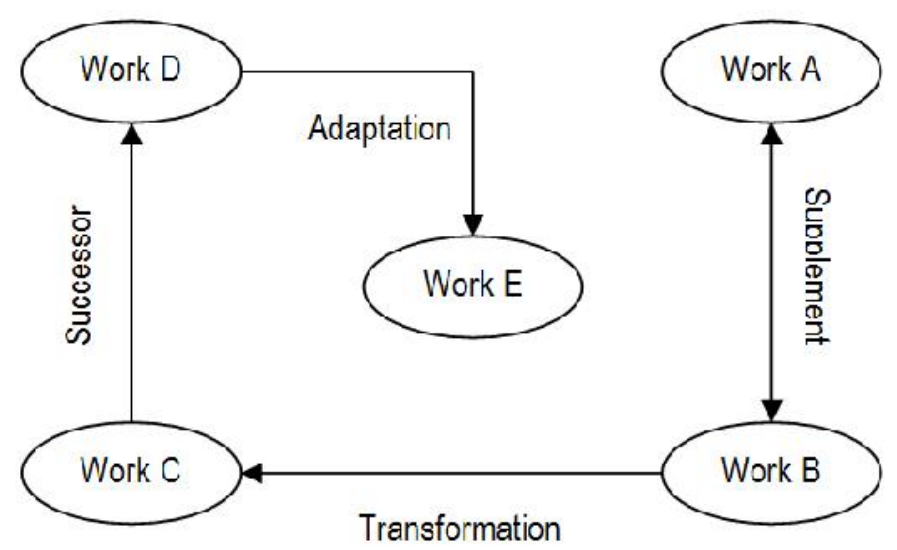

FIGURE 1. Bibliographic Relationships between Works

A lot of attention has been given to the inherent relationships between the entities in the FRBR Group 1 hierarchy. Additionally, there are many other rich content relationships that enable collocation of related items and navigation through the sometimes complex network of the bibliographic universe. ${ }^{5,6}$ The present study focuses on work-to-work bibliographic relationships. The scarcity of literature dealing with the bibliographic relationships of Canadian publications demonstrates the necessity for a study designed to describe their features and characteristics. The current study will do that and also identify, describe and classify the bibliographic relationships on the basis of the FRBR taxonomy (Figure 2).

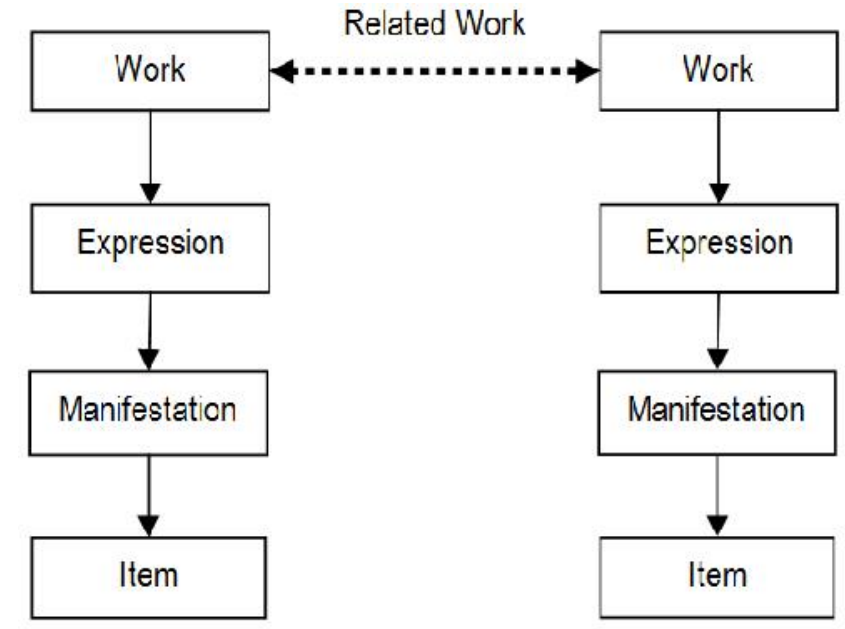

FIGURE 2. Work-to-Work Bibliographic Relationships 
Even though many scholars have pointed out that the FRBR conceptual model could be successfully applied to bibliographic records ${ }^{7,8}$ the usefulness of the model has not been adequately considered and analyzed in the Canadian context. Some researchers have analyzed work types based on the FRBR model, ${ }^{9}$ but little research has been done specifically on work-towork bibliographic relationships from the FRBR point of view.

The effectiveness and efficiency of bibliographic databases depend on identifying and categorizing work-sets as bibliographic families and determining and displaying the type of relationship between bibliographic entities in the bibliographic universe. Finding and collocating related members of these families is a major issue for bibliographic databases, especially online public access catalogs (OPACs).

As mentioned in the FRBR Final Report ${ }^{10}$ there are two types of bibliographic relationships in bibliographic families (work-sets): work-to-work and work-to-expression. The present study attempts to test the FRBR model for identification and categorization of work-to-work bibliographic relationships among Canadian publications and is a novel contribution to the literature on the FRBR bibliographic relationships.

The purpose of this study is to identify and explore the characteristics of Canadian publications. It attempts to answer the following research questions:

- What is the frequency of work-to-work relationships between Canadian publications?

- How are bibliographic relationships in the 10 classes of Dewey Decimal Classification (DDC) different from each other? What proportion of these publications are scattered per each DDC class?

- What proportion of Canadian publications are members of each category of the FRBR taxonomy of work-to-work relationships?

This study also indirectly opens up the following questions: Are the current linking devices in the bibliographic relationships cataloging rules adequate for Canadian publications? If not, how should they be improved?

\section{LITERATURE REVIEW}

As pointed out by Žumer, “. . . after over one decade of study and research on FRBR, we still refer to FRBR as 'the new library model'. This can be explained by the fact that there are not many real-life implementations of FRBR." ${ }^{11}$ Research into the FRBR bibliographic relationships in general and into the work-to-work bibliographic relationships in particular is still in an exploratory phase.

Among the forerunner and most prominent researchers in the field of bibliographic relationships are Tillett, Smiraglia, and Vellucci. In 1987 Tillett, ${ }^{12}$ inspired by the thesaurus relationship taxonomies and through a careful analysis of the Anglo-American Cataloguing Rules, proposed a taxonomy of seven bibliographic relationships: equivalence, derivative, descriptive, whole-part, accompanying, sequential, and shared characteristic. Based on that analytical study, she further examined the occurrence of bibliographic relationships in bibliographic records of different subjects, languages, publication dates, and formats. The Tillett study was a cornerstone piece of research that has inspired many studies to examine the relationship between bibliographic records. As Riva ${ }^{13}$ stated, some of these types of relationships are very broad and also very frequent in bibliographic records, while others occur infrequently. Of the seven classes, derivative is particularly broad ranging. This led Smiraglia ${ }^{14}$, ${ }^{15}$ to focus only on the derivative relationships and to propose a subdivision into seven subclasses as an 
extension to the taxonomy. He proposed a taxonomy of derivative relationships: simultaneous derivations, successive derivations, translations, amplifications, extractions, adaptations, and performances.

In 1997 Vellucci $^{16}$ focused on musical materials where a high intensity of bibliographic relationships exists. She studied the phenomenon of bibliographic families in a music catalog, validating the applicability of six of Tillett's seven classes to music materials (the shared characteristic class is applicable to all materials by default and so was not investigated further), although the subgroups within the categories varied somewhat. She found that nearly $94 \%$ of musical materials bear at least one of the relationships defined by Tillett. Her research indicates that the categories of bibliographic relationships identified by Tillett ${ }^{17},{ }^{18}$ and Smiraglia ${ }^{19}$ are present in the music catalog in large numbers. One should note that these are pre-FRBR studies that include both work-to-work (equivalent to FRBR Table 5.1) relationships and work-set (expression-to-expression, manifestation-to-manifestation, item-to-item) relationships among bibliographic records (covered in FRBR later tables).

Recently, Arastoopoor and Fattahi ${ }^{20}$ studied the typology and terminology of relationships among members of two well-known Persian bibliographic families: the Epic of Kings and the Koran. A sample of 350 records for the Epic of Kings family and a sample of 380 records for the Koran family were selected through a systematic sampling method. This study found that most of bibliographic relationships between entities in these two families are derivative or descriptive. Unsurprisingly, there was no record in the sample pointing to accompanying or sequential relationships, as one really does not expect to find successors of the Koran or other sacred texts. This case study of the two biggest bibliographic families from Iranian publications was based on Tillett's Taxonomy, ${ }^{21}$ not on the taxonomy of relationships in the FRBR Final Report.

Research conducted at $\mathrm{OCLC}^{22}$ on sizes of bibliographic families (about work-set relationships, not work-to-work relationships) showed that a majority of works have only one expression and manifestation, and that only a relatively small number of works have more than one expression. Only about $20 \%$ of all works in WorldCat have more than one manifestation, and about $1 \%$ has more than seven. To some catalogers this means that only a relatively small percentage of a catalog would profit from FRBR, which could bring the viability of FRBR implementation as a whole into question. However, what is usually overlooked is the fact that the latter works have been published in many versions and editions, showing that there is demand for them, and they are central to the users. ${ }^{23}$

\section{MATERIALS AND METHODS}

In the present study, two experiments were conducted: one for detecting bibliographic records with at least one type of relationship and a second to find the DDC class number of given bibliographic records.

One of the first steps in this study was to create a list of keywords (in English and in French) representing work-to-work bibliographic relationships. Keyword searching was used based on a simple assumption that there are key terms representing bibliographic relationships in bibliographic records that may be helpful in identifying and understanding relationships between different bibliographic entities. These terms are generally scattered all over the bibliographic records, especially in titles, statements of responsibility, and notes.

Data was collected in AMICUS (the Canadian national catalog ${ }^{24}$ ). The decision to use this source was primarily based upon the fact that AMICUS is the national catalog of Canada 
maintained by Library and Archives Canada/Bibliothèque et Archives Canada (LAC/BAC), containing over 30 million records, ${ }^{25}$ which is large enough to obtain representative data for Canadian publications in all classes of DDC. Collecting data through an online tool meant, however, that the researchers did not have physical access to the material that was retrieved.

As mentioned, an exhaustive list of English and French keywords ${ }^{26}$ was constructed to represent every bibliographic relationship listed in Table 5.1 (Work-to-Work Relationships) of the FRBR Final Report. In an attempt to find as many records exhibiting a work-to-work relationship as possible we used the "advanced search" function with the "any keywords" key (i.e., all keywords in the record) with a publication date filter set to "2009" and place of publication set to "Canada." Only LAC/BAC contributed monographic records were considered. Searches were carried out during a four-month period between September 1, 2010 and December 22, 2010.

The retrieved bibliographic records were used as the data for the analysis of bibliographic relationships. Each bibliographic record was manually analyzed to determine the type of relationship expressed and to detect false hits. To determine whether the bibliographic records provided sufficient data on the bibliographic relationships, we carefully read bibliographic information in each record, especially the notes. The type of relationship was often clearly indicated in the record: "Suite de: Hush! Hush!" (sequel); "Supplement to: Doelle, Meinhard, 1964- Environmental law" (supplement); "Illustrations taken from the Max \& Ruby animated television series and adapted by Muse Publishing and Communications" (adaptation); "Motion picture based on the novel by Herman Brusselmans" (transformation). In some cases, searching in other bibliographic tools (WorldCat, Amazon, Google Books) was required to determine whether two or more works were related or not. If there were two or more records for the same work (in print, electronic, sound recording, video recording, etc.), only one of them was counted. Records that turned up in more than one search were of course also only counted once.

The frequency of each type of bibliographic relationship was empirically assessed. Analysis was carried out by constructing frequency and cross tables in a spreadsheet. The types of bibliographic relationships were classified and compiled and calculated for analysis. The data collected also included the DDC classes $^{27}$ to allow analysis by discipline.

\section{RESULTS}

The bibliographic relationships found in the Canadian publications that have been selected from the AMICUS catalog were analyzed and classified according to type and DDC classes. According to data obtained from Library and Archives Canada, the total number of monographic records representing manifestations published in Canada in 2009 and cataloged in AMICUS is 28,633 . Our analysis revealed that the total 1,261 records exhibit a work-to-work bibliographic relationship that represents approximately $4.4 \%$ of the population. One should note that this proportion is probably slightly underestimated since according to LAC's bilingual records policy, some manifestations in AMICUS are sometimes linked to two records (e.g., creating two bibliographic records for one book that contains parallel expressions of the same work formatted with two title pages).

Table 1 shows the frequency and percentage of work-to-work bibliographic relationships in each category. The most frequently observed relationship is supplement (59\%), followed by successor $(24 \%)$, transformation $(10 \%)$, and adaptation $(6 \%)$. Together, these four types of relationships account for $98 \%$ of the relationships observed. A close examination of 
supplementary materials reveals that $80 \%$ (595 records) of them are teacher's guides and student manuals. One should remember that the collection used for this study is that of a national library and is undoubtedly somewhat uncharacteristic of most collections. For instance, LAC/BAC receives on legal deposit some types of materials, school texts for instance, that are not collected in all libraries. Considering the strong contribution these materials show to the prevalence of relationships (particularly the supplement type) the collection profile of the database under study is important. Also, LAC/BAC does not receive DVDs and so on on legal deposit and the lack of films might result in an under detection of cases of adaptations, transformations, and imitations.

Finally, the decision to omit serials very likely results in under-reporting for sequential relationships outside of literature.

TABLE 1. Frequency and Percentage of Bibliographic Relationships

\begin{tabular}{|l|c|c|}
\hline Relationship Type & Occurrences & Percentage \\
\hline Supplement & 742 & 59 \\
\hline Successor & 302 & 24 \\
\hline Transformation & 124 & 10 \\
\hline Adaptation & 79 & 6 \\
\hline Complement & 8 & $<1$ \\
\hline Summarization & 6 & $<1$ \\
\hline Imitation & 0 & 0 \\
\hline Total & 1261 & 100 \\
\hline
\end{tabular}

Table 2 shows the frequency of each type of bibliographic relationship in each of the 10 DDC main classes. The data reveals that the majority of successor works (sequel) are in Literature, while the majority of supplements are in Social Sciences, Language, Science, and in Technology. It is also shown that the majority of complements are in the Arts. Also, it is worth noting that adaptations are mainly found in Technology, Arts, and in Literature while the majority of transformations occurred in Arts.

Table 3 presents the frequency and percentage of occurrence of the bibliographic relationships for each DDC class. It shows that Literature (26\%) exhibits the highest number of bibliographic relationships among the ten DDC main classes while Philosophy and Psychology (2\%), and Religion (2\%) had the fewest.

Tables 2 and 3 present frequency data broken up by DDC classes. It should be noted that these are observed frequency without the context of the actual distribution of DDC classes within the whole 2009 population, which probably contains relatively fewer records in the 000,100 , and 200 classes, compared to 300,800 , or 900 to start with.

When comparing the total number of bibliographic relationships in each class of DDC, it was found that approximately $26 \%$ of the bibliographic relationships observed occurred in Literature. This is in accordance with previous studies ${ }^{28}$ where the predominant bibliographic relationships were also in Literature.

Previous studies ${ }^{29}$ also revealed that the frequencies of each type of bibliographic relationship differ for the classes or disciplines, (e.g., Literature, Arts, Science, and Social Sciences). Tillett ${ }^{30}$ and Smiraglia ${ }^{31}$ found that the derivative relationship appeared most frequently in the humanities category. 
TABLE 2. Distribution of Work-to-Work Relationships in Each Class of DDC

\begin{tabular}{|l|c|c|c|c|c|c|c|c|c|c|c|}
\hline & $\mathbf{0 0 0}$ & $\mathbf{1 0 0}$ & $\mathbf{2 0 0}$ & $\mathbf{3 0 0}$ & $\mathbf{4 0 0}$ & $\mathbf{5 0 0}$ & $\mathbf{6 0 0}$ & $\mathbf{7 0 0}$ & $\mathbf{8 0 0}$ & $\mathbf{9 0 0}$ & Total \\
\hline Successor & 5 & 1 & 2 & 4 & 0 & 0 & 4 & 6 & 266 & 14 & 302 \\
\hline Supplement & 33 & 15 & 20 & 156 & 115 & 174 & 167 & 6 & 20 & 36 & 742 \\
\hline Complement & 0 & 0 & 0 & 2 & 0 & 0 & 0 & 6 & 0 & 0 & 8 \\
\hline Summarization & 0 & 0 & 0 & 3 & 0 & 0 & 3 & 0 & 0 & 0 & 6 \\
\hline Adaptation & 3 & 3 & 1 & 5 & 1 & 7 & 10 & 19 & 26 & 4 & 79 \\
\hline Transformation & 0 & 1 & 2 & 5 & 0 & 0 & 1 & 104 & 10 & 1 & 124 \\
\hline Imitation & 0 & 0 & 0 & 0 & 0 & 0 & 0 & 0 & 0 & 0 & 0 \\
\hline Total & 41 & 20 & 25 & 175 & 116 & 181 & 185 & 141 & 322 & 55 & 1261 \\
\hline
\end{tabular}

TABLE 3. Occurrence of Bibliographic Relationships in Each DDC Class

\begin{tabular}{|l|c|c|}
\hline DDC Class & $\begin{array}{c}\text { Number of bibliographic } \\
\text { relationships }\end{array}$ & Percent \\
\hline 000 Generalities & 41 & 3 \\
\hline 100 Philosophy \& psychology & 20 & 2 \\
\hline 200 Religion & 25 & 2 \\
\hline 300 Social sciences & 175 & 14 \\
\hline 400 Language & 116 & 9 \\
\hline 500 Science & 181 & 14 \\
\hline 600 Technology & 185 & 15 \\
\hline 700 Arts \& recreation & 141 & 11 \\
\hline 800 Literature & 322 & 26 \\
\hline 900 History \& geography & 55 & 4 \\
\hline Total & 1261 & 100 \\
\hline
\end{tabular}

\section{OBSERVATIONS}

The FRBR model can be applied to establish relationships in bibliographic databases to support resource discovery. We have tested the AMICUS catalog to estimate the existence of work-towork relationships in Canadian publications. Our data collection process was hindered by the lack of a systematic method to record relationships. Here is summary of the difficulties we encountered.

- Catalogers use a variety of different terms in the note fields to record bibliographic relationships as they are often transcribed from what the authors or publishers have used on the title page. There are many variant words in book titles to indicate a relationship, especially for educational resources (e.g., answer book, answer key, educator guide, educator's companion, instructor guide, parent guide, solutions manual, student book, student guide, student manual, student workbook, students book, students book, students guide, students workbook, teacher book, teacher edition, teacher guide, teacher kit, teacher manual, teacher resource, teacher toolkit, teacher workbook, teachers book, teachers guide, teachers kit, teacher's resource, teachers toolkit, teachers workbook, teaching book, teaching guide, workbook). Therefore it is not easy to design an algorithm to systematically retrieve these records. Relationship should be controlled based on the clear bibliographic relationship designators.

- In some cases we have observed that supplement relationships between two works (e.g., A and B: A has supplement B; B is supplement to A) are not always clearly defined. Sometimes the title of the primary work is not available in the catalog, which leads to blind references. Bibliographic relationships between works are not always mentioned in 
the MARC (Machine Readable Cataloging) relationship fields (770, 772, etc.). We often simply found notes containing expressions such as "Supplement to:" and "Has supplement:" for linking the supplemental works. But specific types of relationships (e.g., novelization) are not clearly defined.

\section{DISCUSSION}

This case study is only one example of work-to-work bibliographic relationships and while issues may vary from country to country, we believe it offers a somewhat unique and different perspective. It seems that the distribution of bibliographic relationships is country and culture dependent. The results of previous studies ${ }^{32}$ show that factors such as country of publication, subject matter, language, publication format, and publication date of the publication, have direct relations to each category of the bibliographic relationships. Smiraglia and Leazer ${ }^{33}$ concluded that "discipline, form, and genre all fail to demonstrate any influence on derivation of works" ${ }^{34}$; but in the same paper they claimed that "discipline appeared to approach statistical significance. ${ }^{, 35}$ In previous studies ${ }^{36}$ the country of publication was considered a very important variable that could have a significant influence on the overall orientation, patterns, and types of publications. Also, and more importantly, the level of completeness of records for different categories of materials can affect which types of relationships are deemed sufficiently important to warrant the research needed to record them accurately.

Overall, this study confirms that bibliographic relationships are prevalent and an important feature of Canadian publications. There are both similarities and differences between our findings and previous research. The results show that approximately 4.4\% of the Canadian 2009 publications recorded in the AMICUS catalog contain a work-to-work bibliographic relationship.

The application of the FRBR model is expected to be more beneficial to certain classes of DDC than others. Since a great proportion of work-to-work relationships were observed in DDC class 800 , resource discovery through explicitly defined relationships in bibliographic records will be especially useful to users who are looking for works of fiction. Findings from this study may provide directions for improvements and new system implementations.

Naturally, a single case study is not enough, although we do not expect any bias, in any direction toward our queries. We presented the results to make our point and to formulate the problem of recognizing work-to-work bibliographic relationships. It would be very interesting to replicate this study using different national bibliographies to obtain comparable data. Further study of specific segments of work-to-work bibliographic relationships is required for developing a more comprehensive taxonomy of bibliographic relationships between related works.

The picture we get from our study is still predominantly Canadian. Additionally, more research should be done on related works and the taxonomy of bibliographic relationships in FRBR and RDA as the cataloging rules applied can affect which types of relationships are deemed important. Are referencing related works devices provided by RDA sufficient? If not, what alternative approaches and techniques could be used to connect related works? 


\section{NOTES}

1. Functional Requirements for Bibliographic Records. Final Report. Approved by the Standing Committee of the Cataloguing Section on September 1997 as amended and correct through February 2009. http://www.ifla.org/files/cataloguing/frbr/frbr_2008.pdf, 55.

2. Ibid., 55-56.

3. Zhang Ying, "Bibliographic Relationships among Chinese Publications: A Bibliographic Study of the Chinese Collections of the East Asia Resources at the University of North Carolina at Chapel Hill" (master's thesis, University of North Carolina, 2003), 5.

4. Zorana Ercegovac, "Multiple-Version Resources in Digital Libraries: Towards User-Centered Displays," Journal of the American Society for Information Science and Technology 57, no. 8 (2006): 1023-1032.

5. Barbara B. Tillett, "Bibliographic Relationships," in Relationships in the Organization of Knowledge, ed. Carol A. Bean and Rebecca Green (Dordrecht: Kluwer Academic Publishers, 2001), 19-35.

6. Barbara B. Tillett, "What is FRBR?: A Conceptual Model for the Bibliographic Universe," The Australian Library Journal 54, no. 1 (2005): 24-30, http://alia.org.au/publishing/alj/54.1/full.text/tillett.html

7. Patrick Le Boeuf, "FRBR and Further," Cataloging \& Classification Quarterly 32, no. 4 (2001): 15-52.

8. Barbara B. Tillett, "FRBR and Cataloging for the Future," Cataloging \& Classification Quarterly 39, no. 3/4 (2005), 197-205.

9. Rick Bennett, Brian F. Lavoie, and Edward T. O'Neill, “The Concept of a Work in WorldCat: An Application of FRBR," Library Collections, Acquisition and Technical Services 27, no. 1 (2003): 45-59, doi:10.1016/S1464-9055(02)00306-8; Akiko Hashizume, "Characteristics of Works in a Japanese Library Catalog from the View Point of FRBR: A Case Study of Keio University Library OPAC Case Study," Library and Information Science no. 58 (2007): 33-48; Jan Pisanski and Maja Žumer, "Functional Requirements for Bibliographic Records: An Investigation of Two Prototypes," Program: Electronic Library and Information Systems 41, no. 4 (2007): 400-417; Jeong-Hyen Kim and Ji-Hyun Moon, "Korean Books and FRBR: An Investigation," Program: Electronic Library and Information Systems 44, no. 3 (2010): 215-228.

10. Functional Requirements for Bibliographic Records, 56.

11. Maja Žumer, "FRBR: The End of the Road or a New Beginning?," Bulletin of the American Society for Information Science and Technology 33, no. 6 (2007): 27-29.

12. Barbara B. Tillett, "Bibliographic Relationships: Toward a Conceptual Structure of Bibliographic Information Used in Cataloging" (PhD diss., UCLA, 1987). 
13. Pat Riva, "Mapping MARC 21 Linking Entry Fields to FRBR and Tillett's Taxonomy of Bibliographic Relationships," Library Resources and Technical Services 48, no. 2 (2004): 130-43.

14. Richard P. Smiraglia, "Authority Control and the Extent of Derivative Bibliographic Relationships" (PhD diss., University of Chicago 1992).

15. Richard P. Smiraglia, "Derivative Bibliographic Relationships: Linkages in the Bibliographic Universe," in Navigating the Networks: Proceedings of the ASIS Mid-Year Meeting, ed. D. L. Andersen, T. J. Galvin, and M. D. Giguere (Medford, NJ: ASIS, 1994), 167-183.

16. Sherry L. Vellucci, Bibliographic Relationships in Music Catalogs (Lanham, MD: Scarecrow Press, 1997).

17. See Tillett, "Bibliographic Relationships."

18. Barbara B. Tillett, "A Taxonomy of Bibliographic Relationships," Library Resources and Technical Services, 35, no. 2 (1991): 150-158.

19. See Smiraglia, "Authority Control and the Extent of Derivative Bibliographic Relationships."

20. Sholeh Arastoopoor and Rahmatollah Fattahi, "Identification and Categorization of Related Works in the Persian Bibliographic Universe: An FRBR Approach," International Cataloguing and Bibliographic Control 39, no. 1 (2010): 12-18.

21. See Tillett, "A Taxonomy of Bibliographic Relationships."

22. Rick Bennett, Brian F. Lavoie, and Edward T. O'Neill, "The Concept of a Work in WorldCat: An Application of FRBR," Library Collections, Acquisition and Technical $\begin{array}{lllll}\text { Services } & 27, & \text { no. } & 1 & \text { (2003), }\end{array}$ http://www.oclc.org/research/publications/archive/2003/lavoie_frbr.pdf

23. Jan Pisanski and Maja Žumer, "Functional Requirements for Bibliographic Records: An Investigation of Two Prototypes," Program: Electronic Library and Information Systems 41, no. 4 (2007), 400-417; also see Žumer, "FRBR."

24. AMICUS: http://www.nlc-bnc.ca/amicus/

25. Library and Archives Canada. "What is AMICUS?", http://www.collectionscanada.gc.ca/amicus/006002-122-e.html

26. English keywords: sequel; prequel; supplement; activity book; adaptation; addenda; addendum; administrator guide; answer book; answer key; based on; educator guide; educator's companion; e-solutions manual; imitation; instructor guide; instructor manual; instructor's resource; lab manual; laboratory manual; literature book; parent guide; parents guide; solution manual; solutions manual; solutions manual; student book; student $\mathrm{CD}$; summarization; summary; teacher's guide; . . . French keywords: cahier d'exercice; cahier d'exercices; cahier d'activités; cahier d'apprentissage; cahier de l'el'eve; cahier de savoirs; cahier des exercices; cahier d'exercices; cahier exercice; corrigé des exercices; 
fichier de l'el'eve; guide d'enseignement; guide d'apprentissage; guide de l'etudiant; guide des étudiants; guide pédagogique; kit d'enseignement; livre d'activités; livre d'exercices; manuel d'enseignement; manuel d'apprentissage; manuel de lecture; manuel de l'el'eve; manuel de l' 'etudiant; ...

27. DDC class numbers were collected from the 082 field of the LAC records when available. If no 082 field was present, data found in the 055 field (LC class number) was used and converted to a DDC number using the conversion table available on OCLC's Question Point reference service (http://www.questionpoint.org/).

28. See Ying, "Bibliographic Relationships among Chinese Publications," Vellucci, Bibliographic Relationships in Music Catalogs, and Bennett, Lavoie, and O'Neill, "The Concept of a Work in WorldCat."

29. See Ying, "Bibliographic Relationships among Chinese Publications" and Tillett, "Bibliographic Relationships."

30. Tillett, "Bibliographic Relationships."

31. See Smiraglia, "Authority Control and the Extent of Derivative Bibliographic Relationships."

32. See Ying, "Bibliographic Relationships among Chinese Publications," Tillett, "Bibliographic Relationships," Smiraglia, "Authority Control and the Extent of Derivative Bibliographic Relationships," and Vellucci, Bibliographic Relationships in Music Catalogs

33. Richard P. Smiraglia and Gregory H. Leazer, "Derivative Bibliographic Relationships: The Work Relationship in a Global Bibliographic Database," Journal of the American Society for Information Science 50, no. 6 (1999): 493-504.

34. Ibid., 503.

35. Ibid., 501.

36. See Ying, "Bibliographic Relationships among Chinese Publications," Tillett, "Bibliographic Relationships," and Vellucci, Bibliographic Relationships in Music Catalogs.

To cite this article:

Arsenault, Clément \& Noruzi, Alireza (2012). Analysis of Work-to-Work Bibliographic Relationships through FRBR: A Canadian Perspective. Cataloging \& Classification Quarterly, 50(5-7), 641-652. http://dx.doi.org/10.1080/01639374.2012.679580 